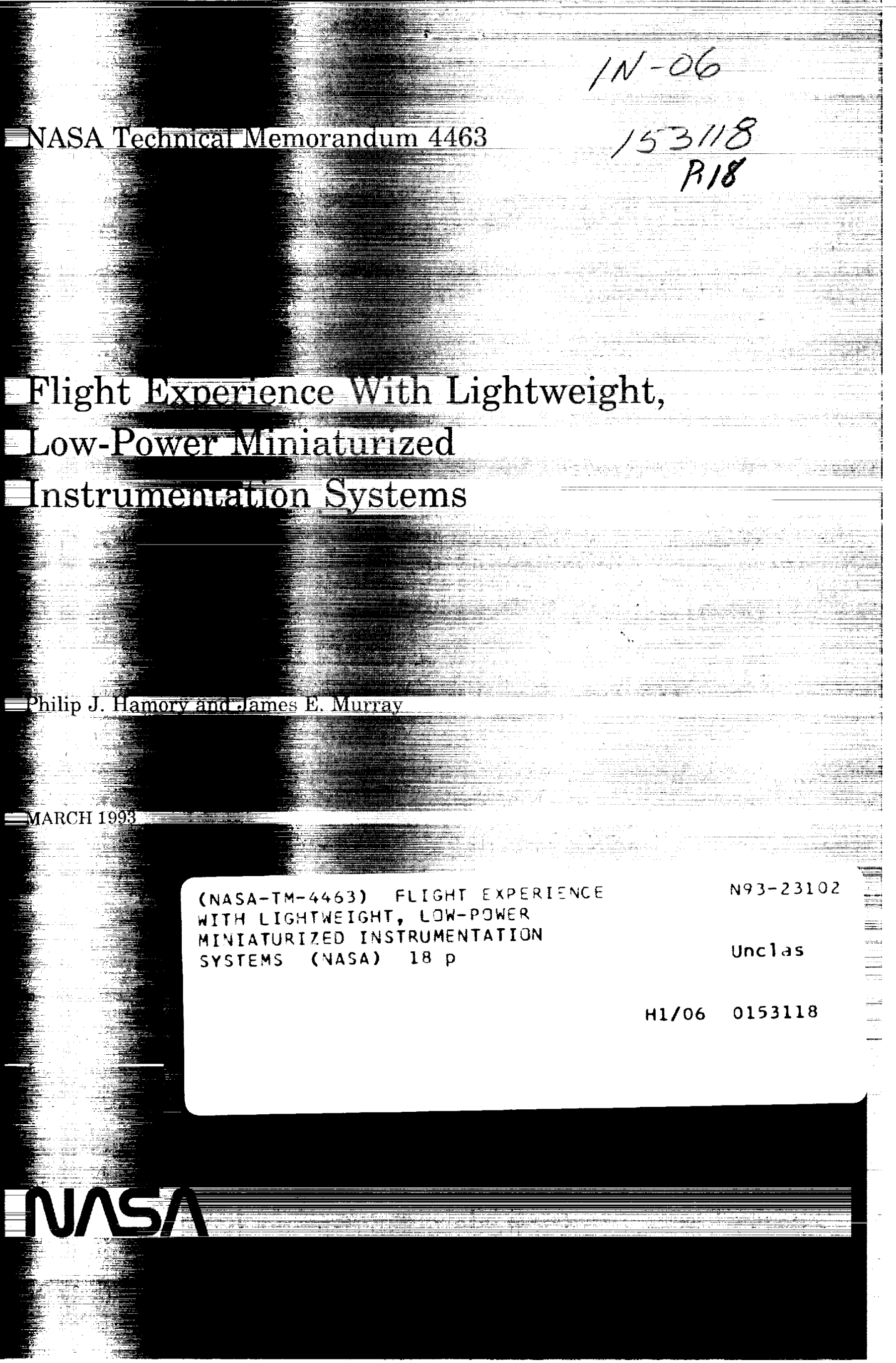


(n)

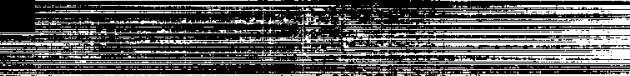

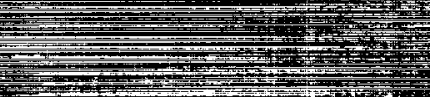

$=3$

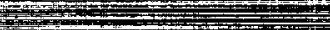

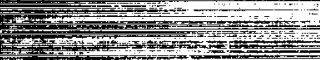

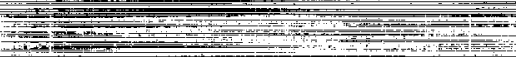

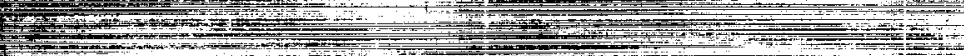

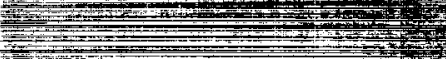

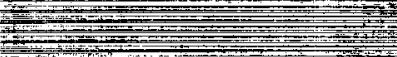

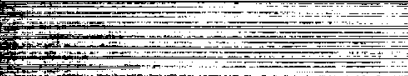

t.

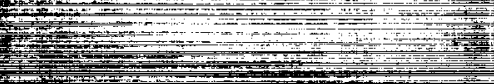

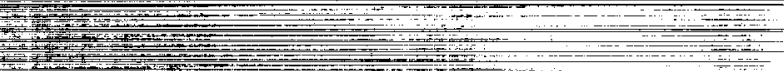

and

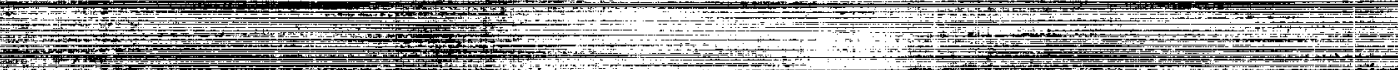

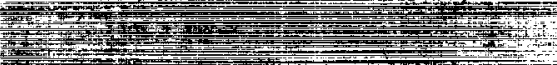

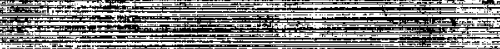

3.t.

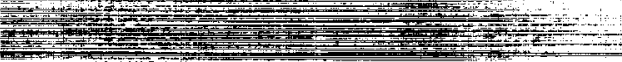

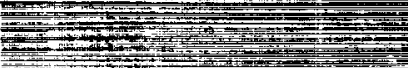

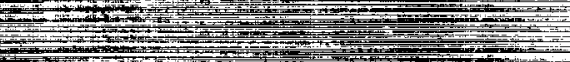

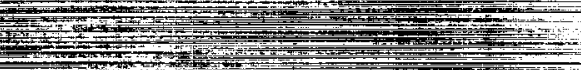

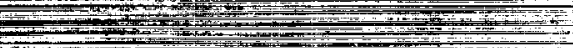

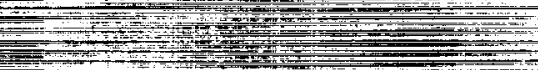

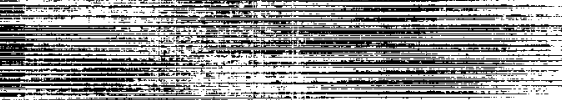

$=13$

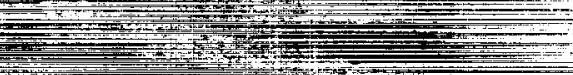

and

.

and

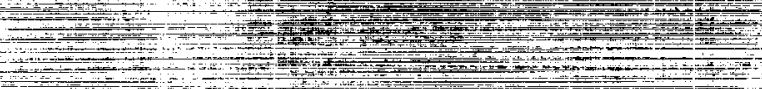

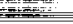

$=$

1.

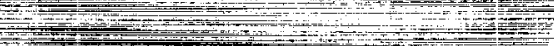

$4=1, y=0$

at 1

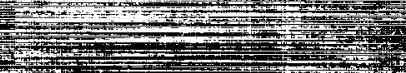

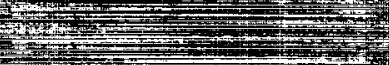

$=$

$x+1=1$

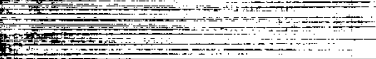

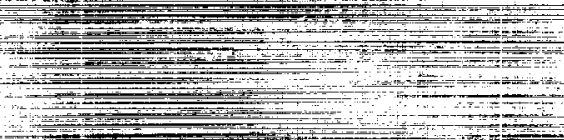

$=0$

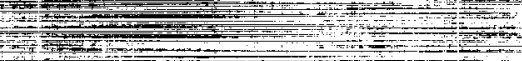

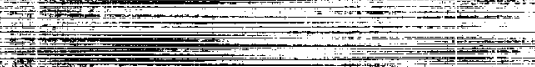

3.

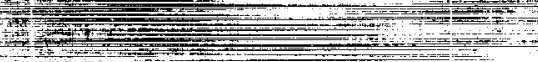

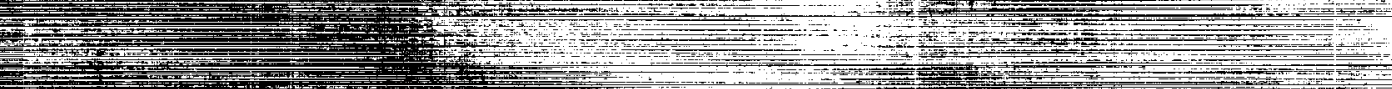

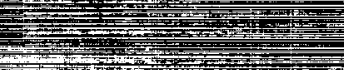

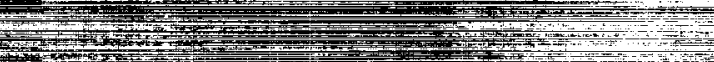

1.t.

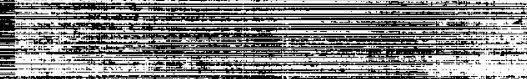

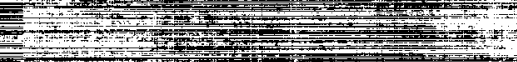

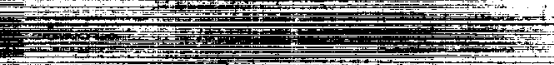

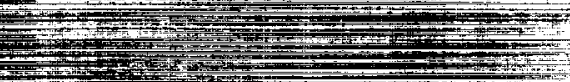

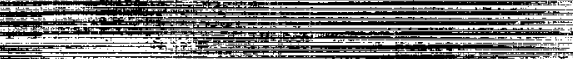

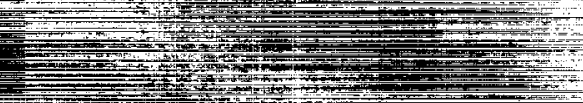

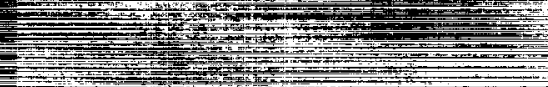

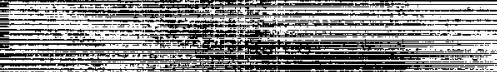

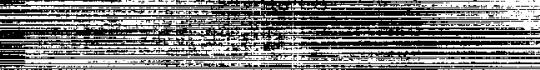

in

$=1$

and

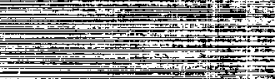

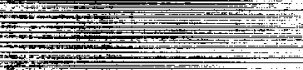

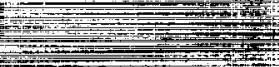

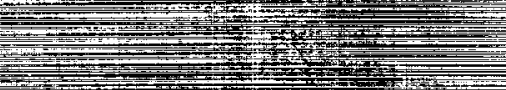

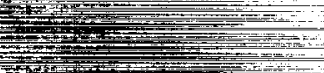

m,

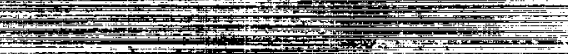

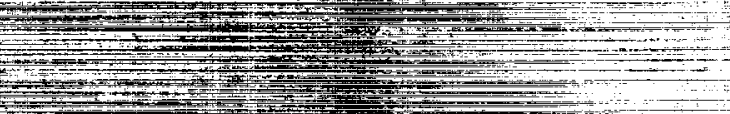

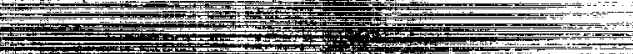

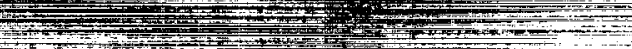

$=12=12=$

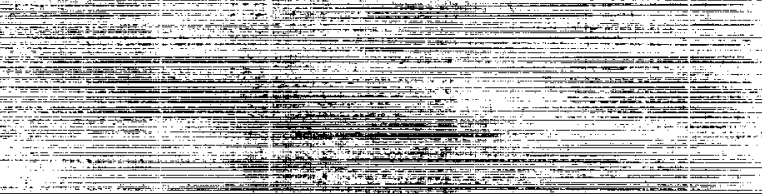

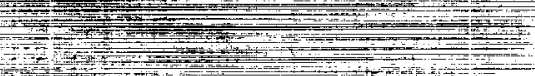

$=$

$=$

$+=$

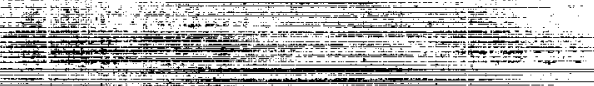

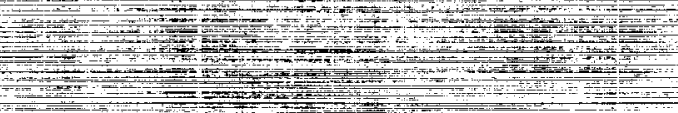

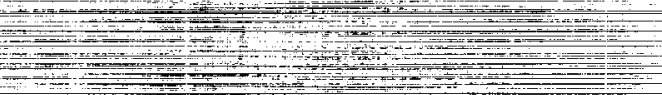

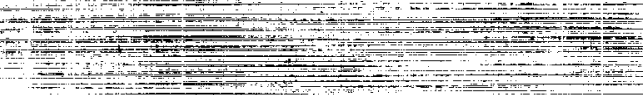

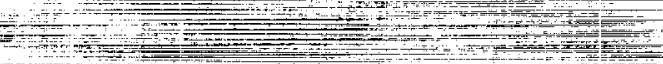


NASA Technical Memorandum 4463

\section{Flight Experience With Lightweight, Low-Power Miniaturized Instrumentation Systems}

Philip J. Hamory and James E. Murray

Dryden Flight Research Facility

Edwards, California

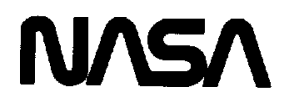

National Aeronautics and Space Administration

Office of Management

Scientific and Technical Information Program

1993 
Use of trade names or names of manufacturers in this report does not constitute an official endorsement of such products or manufacturers, either expressed or implied, by the National Aeronautics and Space Administration. 


\title{
FLIGHT EXPERIENCE WITH LIGHTWEIGHT, LOW-POWER MINIATURIZED INSTRUMENTATION SYSTEMS
}

\author{
Philip J. Hamory* \\ James E. Murray** \\ NASA Dryden Flight Research Facility \\ Edwards, California
}

\begin{abstract}
Engineers at the NASA Dryden Flight Research Facility (NASA-Dryden) have conducted two flight research programs with lightweight, low-power miniaturized instrumentation systems built around commercial data loggers. One program quantified the performance of a radio-controlled model airplane. The other program was a laminar boundary-layer transition experiment on a manned sailplane.

The purpose of this paper is to report NASA-Dryden personnel's flight experience with the miniaturized instrumentation systems used on these two programs. The paper will describe the data loggers, the sensors, and the hardware and software developed to complete the systems. The paper also describes how the systems were used and covers the challenges encountered to make them work. Examples of raw data and derived results will be shown as well. Finally, future plans for these systems will be discussed.

For some flight research applications where miniaturized instrumentation is a requirement, the authors conclude that commercially available data loggers and sensors are viable alternatives. In fact, the data loggers and sensors make it possible to gather research-quality data in a timely and cost-effective manner.
\end{abstract}

\section{Nomenclature}

\section{Acronyms}

A/D analog to digital

CMOS complementary metal oxide semiconductor

CPT control position transducer

\footnotetext{
*Electrical Engineer.

**Aerospace Engineer.

Copyright (C) 1992 by the American Institute of Aeronautics and Astronautics, Inc. No copyright is asserted in the United States under Title 17, U.S. Code. The U.S. Government has a royalty-free license to exercise all rights under the copyright claimed herein for Governmental purposes. All other rights are reserved by the copyright owner.
}

POPU pushover-pullup

RAM random access memory

Symbols

$a_{n} \quad$ normal acceleration, $g$

$a_{x} \quad$ axial acceleration, $\mathrm{g}$

$C_{D} \quad$ vehicle drag coefficient

$C_{L} \quad$ vehicle lift coefficient

$L / D \quad$ lift-to-drag ratio

$\bar{q} \quad$ dynamic pressure, psf

$T \quad$ total thrust, $\mathrm{lb}$

$V_{\text {true }} \quad$ true airspeed, $\mathrm{ft} / \mathrm{sec}$

$\alpha \quad$ angle of attack, deg

$\alpha_{0} \quad$ angle-of-attack breakpoint, deg

$\delta_{e} \quad$ symmetric elevon deflection, deg

$\delta_{e_{\ell}} \quad$ left-elevon deflection, deg

$\delta_{e_{r}} \quad$ right-elevon deflection, deg

$\Delta_{p_{\ell}} \quad$ left-engine static pressure rise, psi

$\Delta_{p_{r}} \quad$ right-engine static pressure rise, psi

\section{Introduction}

Engineers at NASA-Dryden fly radio-controlled model aircraft for preliminary validation of risky design concepts. For programs with limited budgets, the engineers also operate a manned, self-launching sailplane as a low-speed flight research platform. Though the two research efforts are quite different, their instrumentation system requirements are similar. Each system requires up to 24 channels of data acquisition, onboard recording, and operation using batteries, in addition to small size, weight, and price.

The instrumentation systems currently in use at NASA-Dryden are overly complex for these applications. A class of instruments, commonly called data loggers, was investigated as an alternative. Data loggers are commercially available data acquisition 
units with onboard storage. From the Tattletale ${ }^{13}$ line of data loggers, the Model 4 was selected for the radio-controlled model aircraft. Later, when the Model 7 became available, it was selected for the manned sailplane.

This report describes the flight experience gained with miniaturized instrumentation systems built around the Model 4 and Model 7 data loggers. Following a brief outline of the data loggers' features, the report will cover the transducers the data loggers were interfaced to and how they were used. Additional discussions include the software and hardware developed to complete the systems, and the challenges faced in getting the systems to work properly. Examples of raw and derived data will be shown. Finally, future plans for use of these systems will be outlined.

\section{System Description of Tattletale Data Loggers}

\section{Model 4 Data Logger}

The Model 4 data logger contains a 6301 microprocessor (Hitachi America Ltd., San Jose, California), a descendant of the Motorola 6800 microprocessor (Motorola, Inc., Phocnix, Arizona). The Model 4 has 32 kbytes of onboard memory. For measurement of analog signals, the Model 4 has an 11-channel, 10-bit analog to digital (A/D) converter that can operate at up to approximately $600 \mathrm{samples/sec}$. It has an RS232 serial communication port and can be programmed in TTBASIC, which is the BASIC computer language with extra commands for data logging and host interface. Software development can be conducted on an IBM PC ${ }^{\circledR}$ or compatible machine.

The Model 4 measures 3.725 by 2.25 by 0.8 in., weighs $2.2 \mathrm{oz}$, and consumes a maximum of $100 \mathrm{~mW}$. It has an onboard $3-\mathrm{V}$ lithium battery to sustain volatile memory. The internal bus is brought out to 32 pins. These pins are arranged so that one can build a system by stacking memory expansion boards and userdesigned application boards on top of the Model 4.

\section{Model 7 Data Logger}

The Model 7 data logger contains a $68332 \mathrm{mi}-$ croprocessor, a low-power version of the Motorola 68020 microprocessor (Motorola, Inc., Phoenix, Arizona) and has 2 Mbytes of onboard memory. For measurement of analog signals, the Model 7 has a 4-channel, 12-bit A/D converter that can operate at up to 100,000 samples/sec. It has an RS-232 serial communication port and a high-speed parallel interface. The Model 7 is programmed in Think C (Symantec Corp., Cupertino, California). Think $\mathrm{C}$ is an American National Standards Institute (ANSI)-C language

Table 1. Comparison of Tattletale data loggers.

\begin{tabular}{lll}
\hline \hline Specification & Model 4 & Model 7 \\
\hline Microprocessor & 6301 & 68332 \\
Onboard memory & 32 kbytes & 2 Mbytes \\
A/D converter resolution, bits & 10 & 12 \\
$\begin{array}{l}\text { Maximum sample rate, } \\
\quad \text { samples/sec }\end{array}$ & 600 & 100,000 \\
Host computer & (approximate) & \\
& PC compatible & Macintosh \\
& & (PC interface \\
Language & TTBASIC & Planned) \\
RS-232 port & Yes & Yes \\
Parallel port & No & Yes \\
Battery-backed RAM & Yes & No \\
Hard drive & No & Yes (up to 80 Mbytes) \\
Real-time clock & No & Yes \\
Size, in. & 3.725 by 2.25 by 0.8 & 4.0 by 2.75 by 0.44 \\
Weight, oz & 2.2 & 2.5 \\
Weight including hard drive, oz & --- & 8 \\
Maximum power consumption, $m W$ & 100 & 500 \\
Typical power with hard drive, $W$ & --- & 3 \\
Approximate cost with startup materials & $\$ 500$ & $\$ 3300$ \\
\hline \hline
\end{tabular}

\footnotetext{
( Tattletale is a registered trademark of Onset Computer Corp., North Falmouth, Massachusetts.
}

(1BM PC is a registered trademark of the IBM Corp, Armonk, New York. 
development environment. Software development can be conducted on a Macintosh ${ }^{\circledR}$ computer .

The Model 7 measures 4.0 by 2.75 by 0.44 in., weighs $2.5 \mathrm{oz}$, and consumes a maximum of $500 \mathrm{~mW}$. It is also designed to interface to a hard drive, the same kind of drive used in many laptop computers. The hard drive adds $1 \mathrm{in}$. to the vertical measurement and $5.5 \mathrm{oz}$ to the total weight. As with the Model 4, user-designed application boards can be stacked upon the Model 7 and interfaced to a 120-pin internal bus.

\section{Flight Experience With a Radio-Controlled Model Aircraft}

\section{Test Objective}

The Model 4 has been used on several model aircraft flight programs where research-quality data were required for quantitative analysis. An objective of one of these flight programs was to measure the performance of the test aircraft, which was powered by two ductedfan engines. Performance parameters of interest were the lift-curve slope, the lift-to-drag ratio, and the trim curve.

\section{Maneuver Design}

A flight test maneuver commonly used to quantify aircraft performance is a quasi-static pushover-pullup (POPU). Properly executed, a single POPU maneuver can simultaneously characterize the lift curve, the lift-to-drag ratio, and the trim curve over a large angleof-attack range. ${ }^{1}$ For its simplicity, the POPU maneuver was initially selected as the primary maneuver for performance measurement. acceleration ( $a_{x}$ and $a_{n}$, respectively), angle of attack $(\alpha)$, dynamic pressure $(\vec{q})$, and thrust $(T)$.

Accurate measurement of the thrust produced by the ducted-fan engines was central to obtaining accurate drag measurements. An engine and fan assembly was calibrated in a wind-tunnel test program. Then a model of engine thrust as a linear function of dynamic pressure and static pressure rise across the fan assembly was obtained. Measurement of in-flight thrust also required measurement of the static pressure rise across the left- and right-fan assembly, $\left(\Delta_{p_{\ell}}\right.$ and $\Delta_{p_{r}}$, respectively). Measurement of the trim curve also required measurements of the elevon control surface deflections $\left(\delta_{e_{\ell}}\right.$ and $\left.\delta_{e_{r}}\right)$.

Because of size and weight constraints, no lateral- or directional-axis variables were measured. All test maneuvers were flown while minimizing cross-axis motion; the analysis assumed purely longitudinal motion.

The selection of scnsors for the test program was driven primarily by weight and power considerations. Table 2 presents sources and specifications for the sensors used in the test program.

\section{Instrumentation System}

The Model 4 was the core of the instrumentation system used on the model aircraft. A 128 kbyte memory expansion board was added to increase data storage capability to approximately 150 kbytes. Two application boards were also needed to complete the hardware. These were designed at NASA-Dryden and consisted of an analog multiplexer board and a power supply

Table 2. Sensor specifications.

\begin{tabular}{llccc}
\hline \hline Variable & Model number & Range & Resolution & Accuracy \\
\hline$\alpha, \mathrm{deg}$ & NASA-Dryden noseboom & -5 to 40 & 0.04 & 0.25 \\
$\bar{q}, \mathrm{ps}$ & SenSym 142SC01D* & 0 to 55 & 0.058 & 0.144 \\
$\delta_{e_{\ell}}, \mathrm{deg} ; \delta_{e_{r}}, \mathrm{deg}$ & NASA-Dryden CPT & -40 to 20 & 0.06 & 0.20 \\
$\Delta_{p_{\ell}}, \mathrm{psi} ; \Delta_{p_{r}}$, psi & SenSym 142SC01D* & 0.0 to 0.6 & 0.0006 & 0.001 \\
$a_{x}, \mathrm{~g}$ & IC Sensors 3110-002 & -1 to 1 & 0.002 & 0.015 \\
$a_{n}, \mathrm{~g}$ & IC Sensors 3110-005 & -0.5 to 2.5 & 0.003 & 0.02 \\
\hline
\end{tabular}

"SenSym Inc., Sunnyvale, California.

**IC Sensors, Milpitas, California.

\section{Measurement Requirements and Sensor Selection}

Minimum measurement requirements for the test program were determined from the test requirements and maneuver selection. Measurement of the aerodynamic forces (lift and drag) and their nondimensional coefficients required measurement of axial and normal

\footnotetext{
(ब) Macintosh is a registered trademark of Apple Computer, Inc., Cupertino, California.
}

board. The circuitry for each channel on the multiplexer board consisted of a differential amplifier, a third-order Butterworth low-pass filter, and a complementary metal oxide semiconductor (CMOS) switch. The schematic is shown in Fig. 1. The power supply board provided voltage regulation and excitation to the sensors, and contained a voltage reference for the A/D converter. Figure 2 shows the complete data acquisition system including the Model 4 , the memory expansion board, application boards, battery pack, and all sensors. These components weighed $1.7 \mathrm{lb}$ 
and consumed $500 \mathrm{~mW}$ of power. Figure 3 shows the Model 4 package installed in the nose section of the model aircraft.

The instrumentation system is incomplete without software. Three software modules were required to operate and obtain data from the system. The first module controlled the Model 4 in flight. The second module downloaded fight data from the Model 4. The third module converted the raw flight data into an engincering format compatible with software used on several computers at NASA-Dryden. The first and third modules were written at NASA-Dryden in TTBASIC and FORTRAN 77, respectively. The second module, Procomm (Datastorm Technologies, Inc., Columbia, Missouri), was obtained commercially.

Only the first module ran on the Model 4. It was uploaded from the PC compatible before flight and was left in standby mode. At the runway, a ground operator threw a switch to start data logging and released the aircraft for takeoff. The Model 4 recorded eight channels of data continuously at 25 samples/sec. Data logging stopped automatically in approximately $6 \mathrm{~min}$ when random access memory (RAM) was full.

The other two modules ran on the PC compatible. By using an 8086 class PC compatible, a flight's data set ( 150 kbytes) could be downloaded in approximately 6 min and converted to engineering format in approximately $30 \mathrm{~min}$. Though the total time is comparatively long, it was adequate for the project needs. The total time can be shortened by using a more powerful PC compatible.

\section{Implementation Challenges}

In anticipation of potential interference between the avionics and instrumentation systems, the power switch for the instrumentation system was attached to a servoactuator of the avionics system. This gave the pilot the ability to turn the instrumentation system on or off in flight. Likewise, the model aircraft receiver was programmed to turn off the instrumentation system automatically upon loss of the transmitter signal. The logger program and any data gathered would not be lost upon shutdown because of the $3-\mathrm{V}$ backup battery.

There was never any interference between the systems in flight. However, getting the systems to work together on the ground was a major challenge initially.

From successful noninstrumented flights it was clear that the avionics system worked. From practice flights using a different model airplane it was also clear that the instrumentation worked. However, for an unknown reason, the preflight checks sometimes failed with the instrumentation system in place and turned on. Different transmitters, receivers, uplink frequencies, and antenna orientations were tried without success. Boosting uplink power from 0.5 to $5 \mathrm{~W}$ provided some improvement; however, upon elimination of an intermittent ground loop in the instrumentation the preflight checks succeeded consistently.

The high-vibration environment in the model aircraft provided another challenge. At high power settings, the structural vibration from the reciprocating engines was in excess of $5 \mathrm{~g}$. This overwhelmed the lower level acceleration signals from the lift and drag forces during the test maneuver. Different mounting techniques and mounting locations for the engines and accelerometers were attempted but failed to alleviate the problem. Ultimately, a "pullup" maneuver was developed that could be flown with the engines at an idle power setting. Under these conditions the accelcrometer data were suitable for analysis.

\section{Results of Model Aircraft Flights}

Figure 4 shows a time history of a representative pullup maneuver. Included are the raw measured variables, $\alpha, \bar{q}, \delta_{e_{\ell}}, \delta_{e_{r}}, \Delta_{p_{\ell}}, \Delta_{p_{r}}, a_{n}$, and $a_{x}$, as well as the derived variables true airspeed $\left(V_{\text {true }}\right)$, lift coefficient $\left(C_{L}\right)$, drag coefficient $\left(C_{D}\right), T$, and lift-to-drag ratio $(L / D)$. Light turbulence is evident in $\alpha, a_{n}$, and $a_{x}$.

Figures 5, 6, and 7 show results derived from the time history data shown in Fig. 4. The turbulenceinduced and other noises were removed from a subset of the raw data using a digital low-pass filter, and these data were used in the following results.

Figure 5 shows the flight-determined lift curve for the aircraft. The small symbols represent the $C_{L}$ and angle-of-attack measurements at each sample point, and the solid line is a piecewise linear fit to the data points. There is a change in slope at $\alpha=\alpha_{0}$ where the acrodynamics of the aircraft change character. Both above and below $\alpha=\alpha_{0}$ the slope is consistent.

Figure 6 shows the flight-detemined lift-to-drag ratio for the aircraft. The small symbols represent the $L / D$ measurements at each sample point, and the solid line is a hand-faired estimate through the data points. The dotted lines above and below the solid lines are estimates of the error bounds for the data based on instrumentation error estimates, data repeatability, maneuver quality, and signal-to-noise ratio.

Figure 7 shows the flight-determined trim curve for the aircraft. The small symbols represent the $\delta_{e}$ and angle-of-attack measurements at each sample point, and the solid line is a piecewise linear fit to the data points. As with the lift curve shown in Fig. 5, there is definite change in the trim curve at approximately $\alpha=\alpha_{0}$, where there is a measurable change in the aircraft acrodynamics. 


\section{Flight Experience With a Manned Sailplane}

\section{Test Objective}

For programs with limited budgets, a self-launching sailplane (shown in Fig. 8) serves as a low-speed flight research platform. The objective of one flight program was to determine the maximum size of excrescence tolerable on a laminar-flow wing before boundary-layer transition occurs. Excrescences are rough spots on a surface.

\section{Experiment Design}

A set of calibration flights determined the natural boundary-layer transition location on the wing. In subsequent flights, excrescenses of varying thickness were applied to the wing, and changes in the boundary-layer transition location were observed. The excresences were simulated by using vinyl sheets 0.032 in. or less in thickness. The sheets were wrapped around the leading edge of the wing leaving an aft-facing step as shown in Fig. 9. Maneuvers were flown 5000 to $10,000 \mathrm{ft}$ above sea level, and straight and level flight was used to obtain stabilized data.

\section{Measurement Requirements}

To pinpoint transition location, an array of hot films (shown in Fig. 10) was laid on the wing such that part of the array would see laminar flow and part would see turbulent flow. Hot-film anemometers developed at NASA-Dryden ${ }^{2}$ provided signal conditioning for the hot films. Figure 10 shows the hot-film array on the wing. It was a requirement to record eight of the hotfilm signals at 1500 samples/sec.

Airdata parameters such as outside air temperature, airspeed, and altitude were also measured. For expediency, these measurements were not recorded electronically. Rather, the pilot read the measurements from the cockpit instrument panel and noted them on the flight card. The pilot also noted the time for correlation to the electronic data.

\section{Instrumentation System}

The Model 7 was the core of this instrumentation system. The Model 7 was selected for its high sampling rate capability and greater data storage capacity.

Two application boards were stacked on the Model 7 to complete the system. One was an eight-channel ana$\log$ multiplexer board, and the other was a power supply board. Both were designed at NASA-Dryden. The circuitry for each channel on the multiplexer board consisted of a differential amplifier and a CMOS switch. Overvoltage protection for the A/D converter inputs, a lamp driver, and triggering circuitry were included on this board as well. No anti-aliasing was included be- cause it existed on the ancmometers. A patch panel between the anemometers and the multiplexer board provided easy selection of hot films between flights. The power supply board provided voltage regulation and a voltage reference for the system as well as a voltage offset for the differential amplifiers on the multiplexer board.

Figure 11 shows the Model 7, the analog multiplexer board, and power supply board. Also shown is one of the anemometers and the 72-Whr nickel-cadmium battery pack that powered the entire system. The size of the battery pack was driven by three factors: (1) the power requirements of the anemometers, (2) the flight time, and (3) the need to provide reserve capacity to power instrumentation added in the future. The anemometer chassis consumed up to $23 \mathrm{~W}$ when fully stocked and flights generally lasted $1 \mathrm{hr}$. The Model 7 package alone consumed only $0.9 \mathrm{~W}$. Figure 12 shows the battery pack, Model 7 chassis, and anemometer chassis installed in the cockpit.

Three software modules were required to operate and obtain data from the system. The first module controlled the Model 7 in flight. The second module operated the parallel interface and downloaded data from the Model 7. The third module converted the raw flight data into a format readable by plotting software available for the Macintosh computer. The three modules were written at NASA-Dryden in C.

Only the first module ran on the Model 7. It was uploaded from the Macintosh computer before flight and it remained in standby mode. When triggered by the pilot, it turned on a lamp in the cockpit, gathered eight channels of hot-film data at a rate of 1500 samples/sec for $4 \mathrm{sec}$, turned off the lamp, and waited for the next trigger. Data for up to 10 maneuvers could be captured in this manner during 1 flight.

The other two modules ran on the Macintosh computer. A flight's data set (1 Mbyte) could be downloaded in approximately $3 \mathrm{~min}$, and conversion of the data from binary format only required a few minutes. Hence, flight data were available quickly after landing.

\section{Implementation Challenges}

The major challenge involved triggering the system. Initially, the triggering circuitry consisted of a digital input pin on the Model 7, a $100 \mathrm{k} \Omega$ pullup resistor, and a 6 - $\mathrm{ft}$ wire to a switch on the control stick. This circuitry was susceptible to false triggering upon engine startup.

To solve the triggering problem, a $1-\mu \mathrm{F}$ capacitor was attached to the digital input pin, and the pullup resistor was reduced to $1 \mathrm{k} \Omega$. However, for added robustness, the software was changed to look for a trigger pulse lasting at least $0.25 \mathrm{sec}$. Previously it had only 
looked for a momentary trigger. Furthermore, a lamp in the cockpit, previously illuminated only while data were being gathered, was programmed to blink once every 10 sec after the memory was filled. This provided some visible indication of the system's state.

\section{Results of Sailplane Flights}

Figure 13 shows a time history of eight hot films for one maneuver conducted at 70 knots during a smoothwing flight; that is, a flight without excrescences. The signals are offset by chord location measured in percent chord. The lower amplitude signals, such as those from 22.6 to 59.2 percent chord, indicate laminar flow. The large amplitude signal at 62.8 percent indicates turbulent flow. Thus the transition location for this maneuver was between 59.2 and 62.8 percent chord.

Figure 14 shows results derived from flights with aftfacing steps located at 42.6-percent chord. The transition location resulting from step heights of 0.012 , 0.015 , and 0.020 in. are compared with the transition location of the smooth wing. Notice that with all step heights the transition location moves forward. Whereas the location resulting from step heights 0.012 in. and $0.020 \mathrm{in}$. appear to be independent of Reynolds number, the location resulting from the 0.015 -in. step moves forward at Reynolds numbers greater than 1 million.

\section{Future Plans}

\section{System Architecture}

For applications where a data logger is appropriate, plans call for use of the Model 7. Designs for the analog multiplexer and power supply boards will be finalized and printed circuit boards will be manufactured. The boards flown on the manned sailplane were prototypes wired at NASA-Dryden upon blank prototyping boards available from the manufacturer. The printed circuit boards will have slightly larger dimensions than the Model 7 in order to improve the system's structural integrity.

Currently, a stack of boards is held together by four screws. These four screws are not located in the corners, so the ends of the boards can bend when experiencing vibration. Application boards designed in-house will have an extra $1 / 16$-in. on each side so that the boards can slide into grooves within a box. The grooves will keep the ends of the boards rigid. With this modification, a stack should be able to withstand greater vibration.
The high-speed parallel interface between the Model 7 and the Macintosh computer will be repackaged as well. The interface currently resides on a tiny circuit board connected perpendicularly to the Model 7. It will be redesigned in-house to attach in parallel and will have the extra 1/16 in. on each side as mentioned previously. The header strip will be replaced by a D-subminiature connector. These enhancements will make the interface more practical to work with.

\section{System Applications}

Eventually this may develop into a "shoebox" instrumentation system; that is, a self-contained system, approximately the size of a shoebox. This system would be capable of measuring the basic parameters needed to determine an aircraft's performance: accelerations, rates, positions, pressures, and temperatures. In addition, this would be a system that could be rapidly installed on an aircraft to address last-minute needs or to support projects with very short lead times.

\section{Concluding Remarks}

The flight programs described acquired researchquality data in a timely and cost-effective manner using instrumentation systems built around commercially available data loggers and sensors. Data loggers are well suited for applications requiring miniaturized instrumentation and onboard recording

The data loggers provide large bandwidth and onboard storage capabilities in a small-sized and lowpower package. In the case of the sailplane program, eight channels of data were acquired at $1500 \mathrm{sam}$ ples/sec for $40 \mathrm{sec}$ with 12-bit (0.024-percent) resolution. The package measured approximately 4 by 2.75 by $2.5 \mathrm{in}$, weighed approximately $8 \mathrm{o} z$ and consumed approximately $900 \mathrm{~mW}$ of power.

\section{References}

\footnotetext{
${ }^{1}$ Iliff, Kenneth W., "Maximum Likelihood Estimation of Lift and Drag from Dynamic Aircraft Maneuvers," J. of Aircraft, vol. 14, no. 12, Dec. 1977, pp. $1175-1181$.

${ }^{2}$ Chiles, IIarry R., The Design and Use of a Temperature-Compensated Hot-Film Anemometer System for Boundary-Layer Transition Detection on Supersonic Aircraft, NASA TM-100421, 1988.
} 


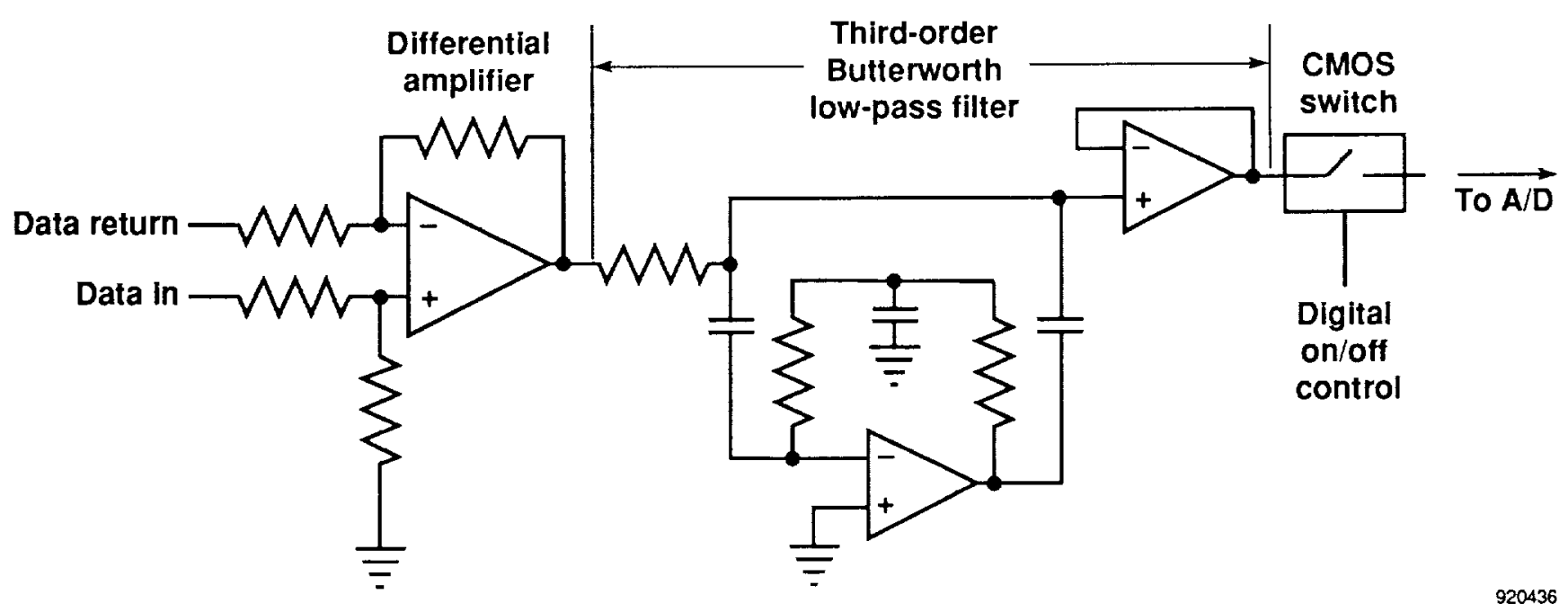

Fig. 1 One channel of analog multiplexer board used with the Model 4. 


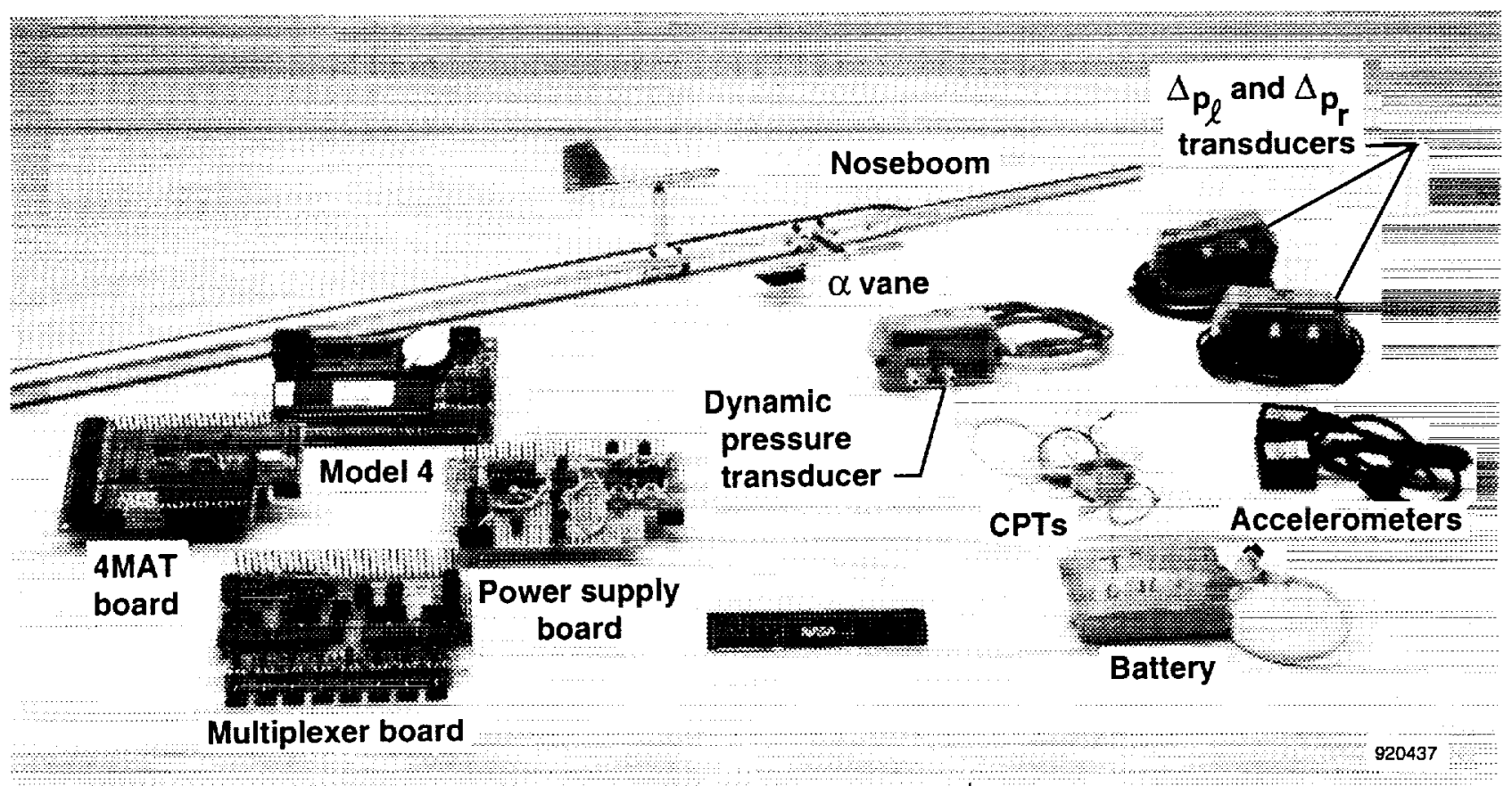

Fig. 2 Model 4 onboard data acquisition components.

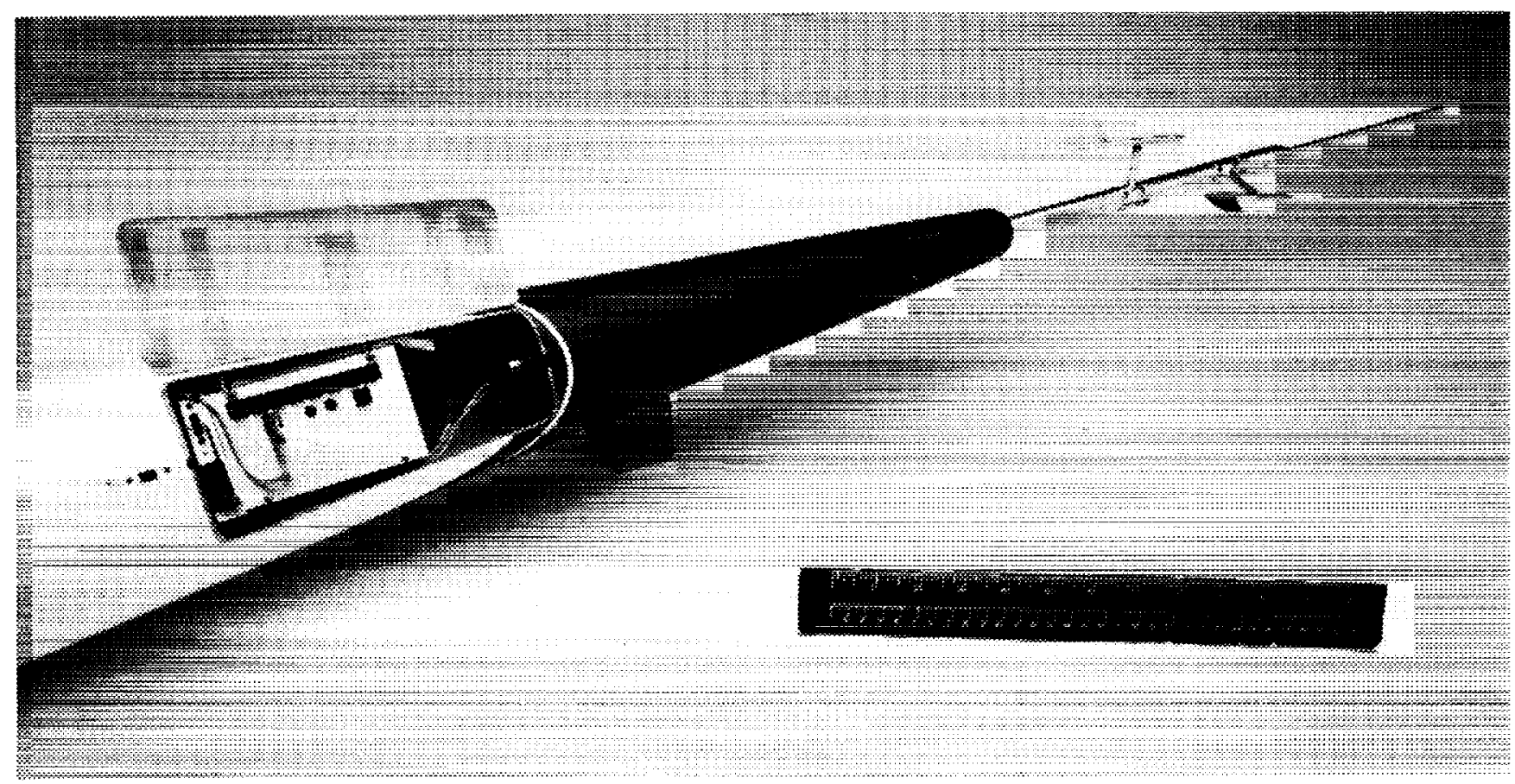

Fig. 3 Model 4 package installed in model aircraft. 

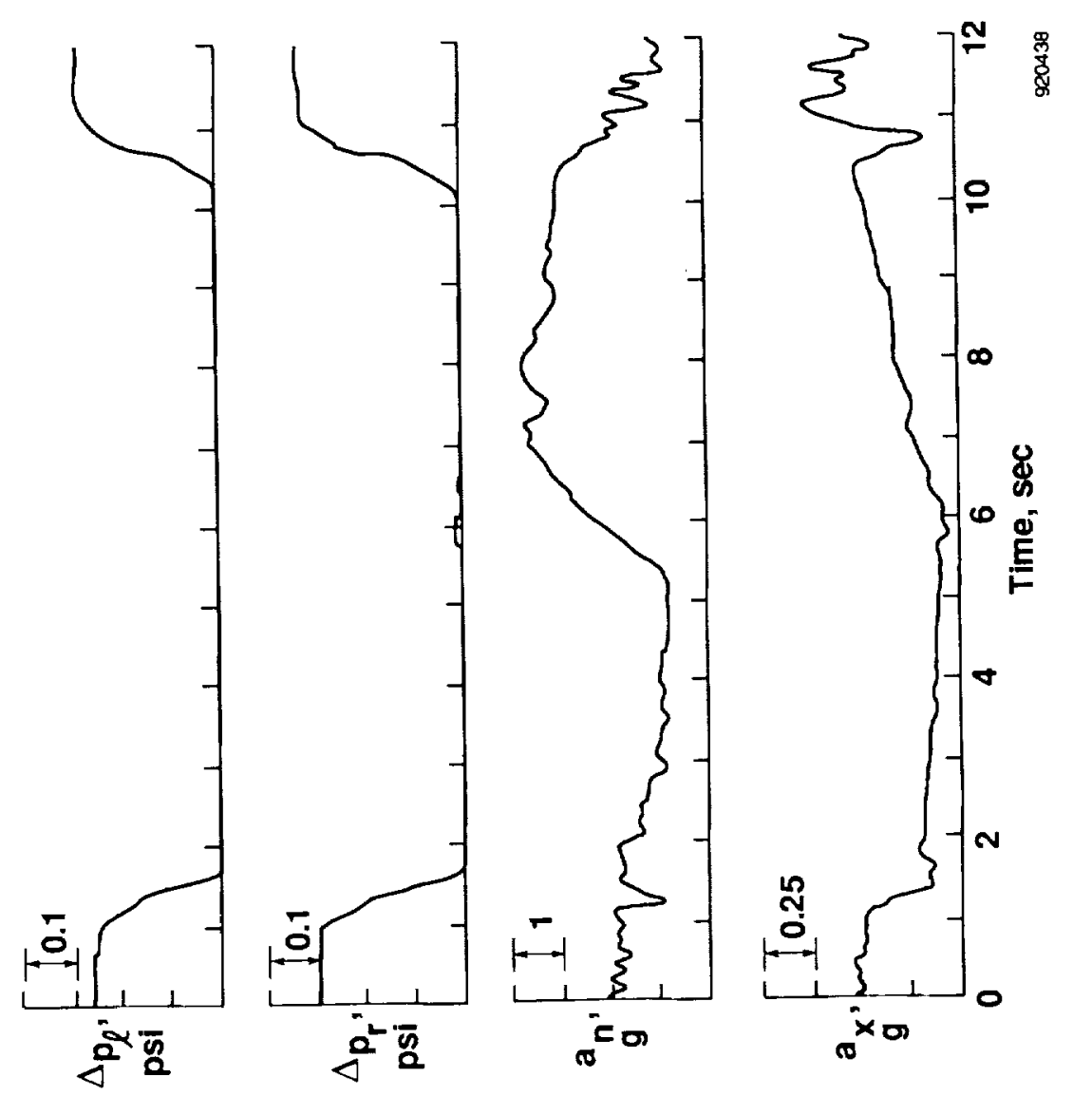

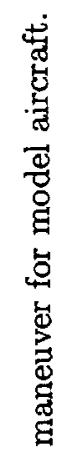
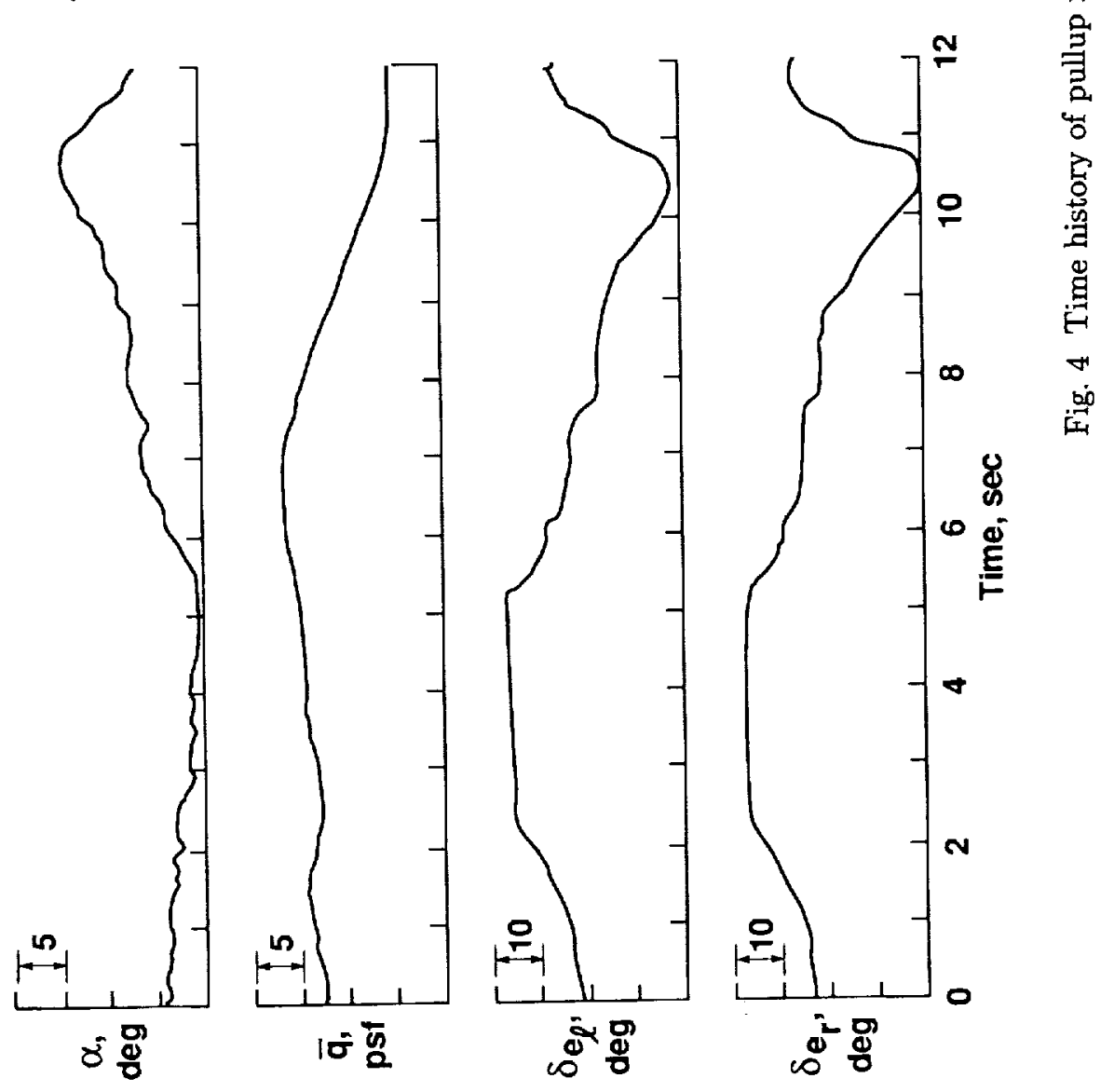


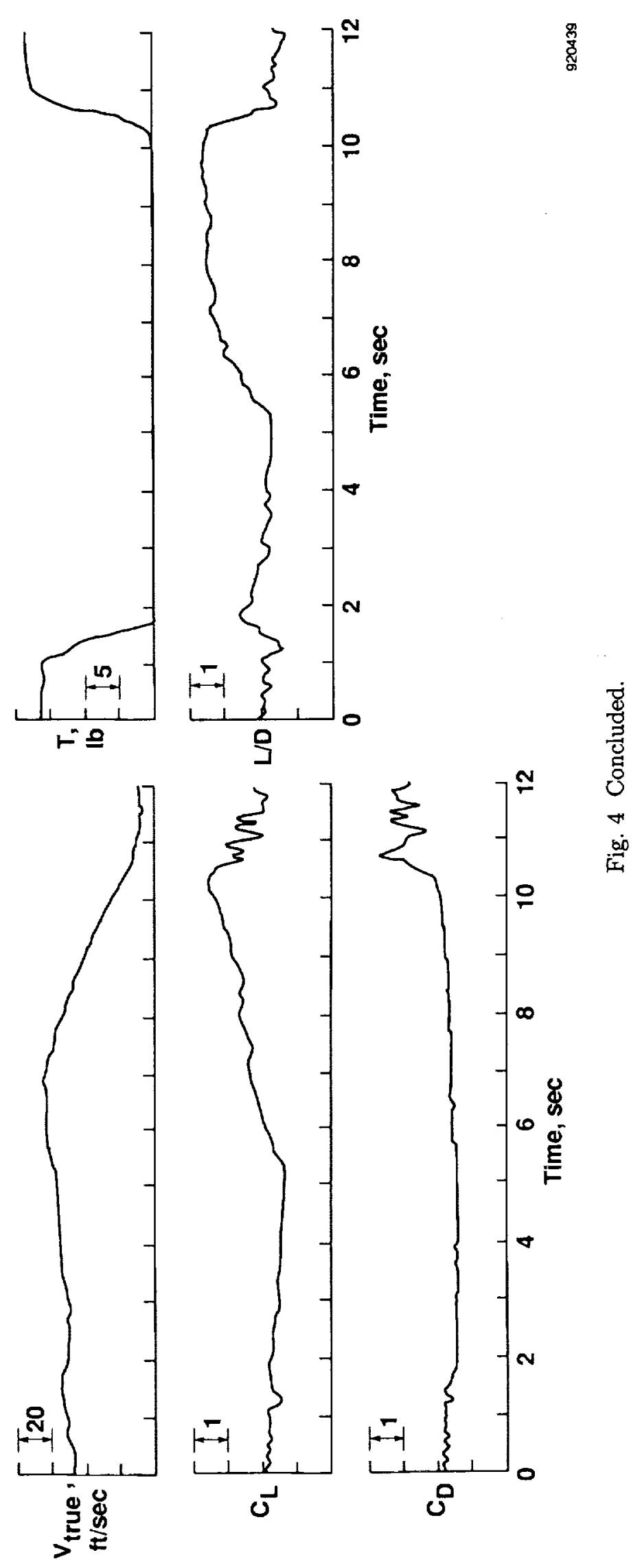




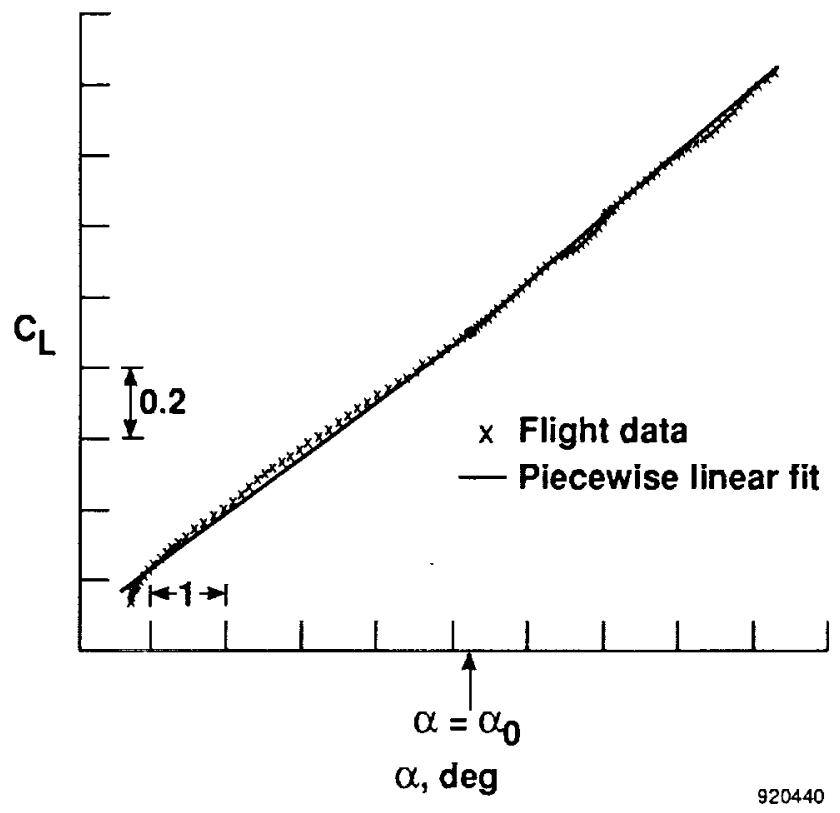

Fig. 5 Flight-determined lift curve for model aircraft.

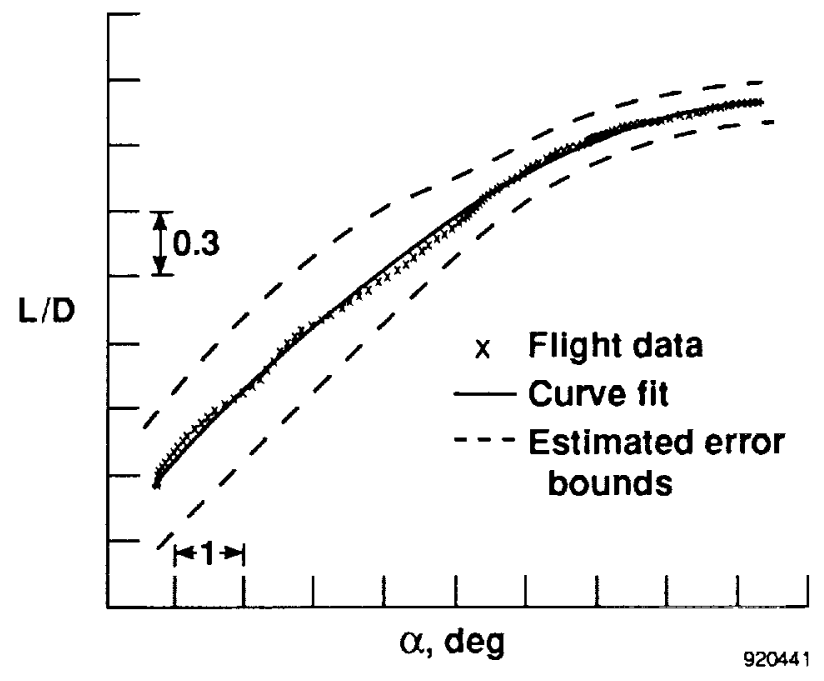

Fig. 6 Flight-determined lift-to-drag ratio for model aircraft.

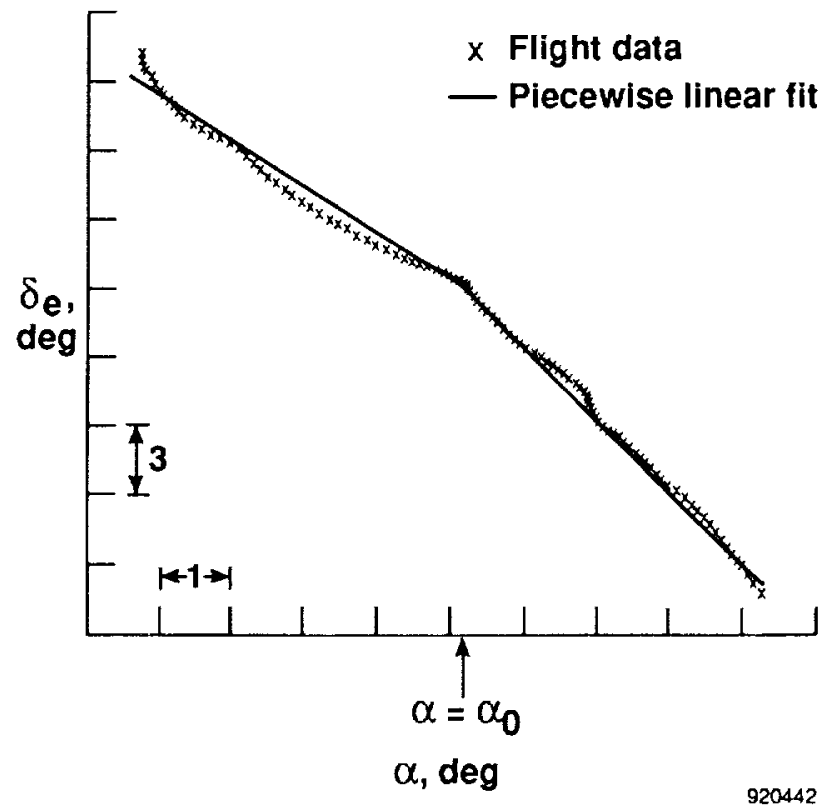

Fig. 7 Flight-determined trim curve for model aircraft. 
ORIGINAL PAGE.

gLaCK AND WHITE PHOTOGRANH

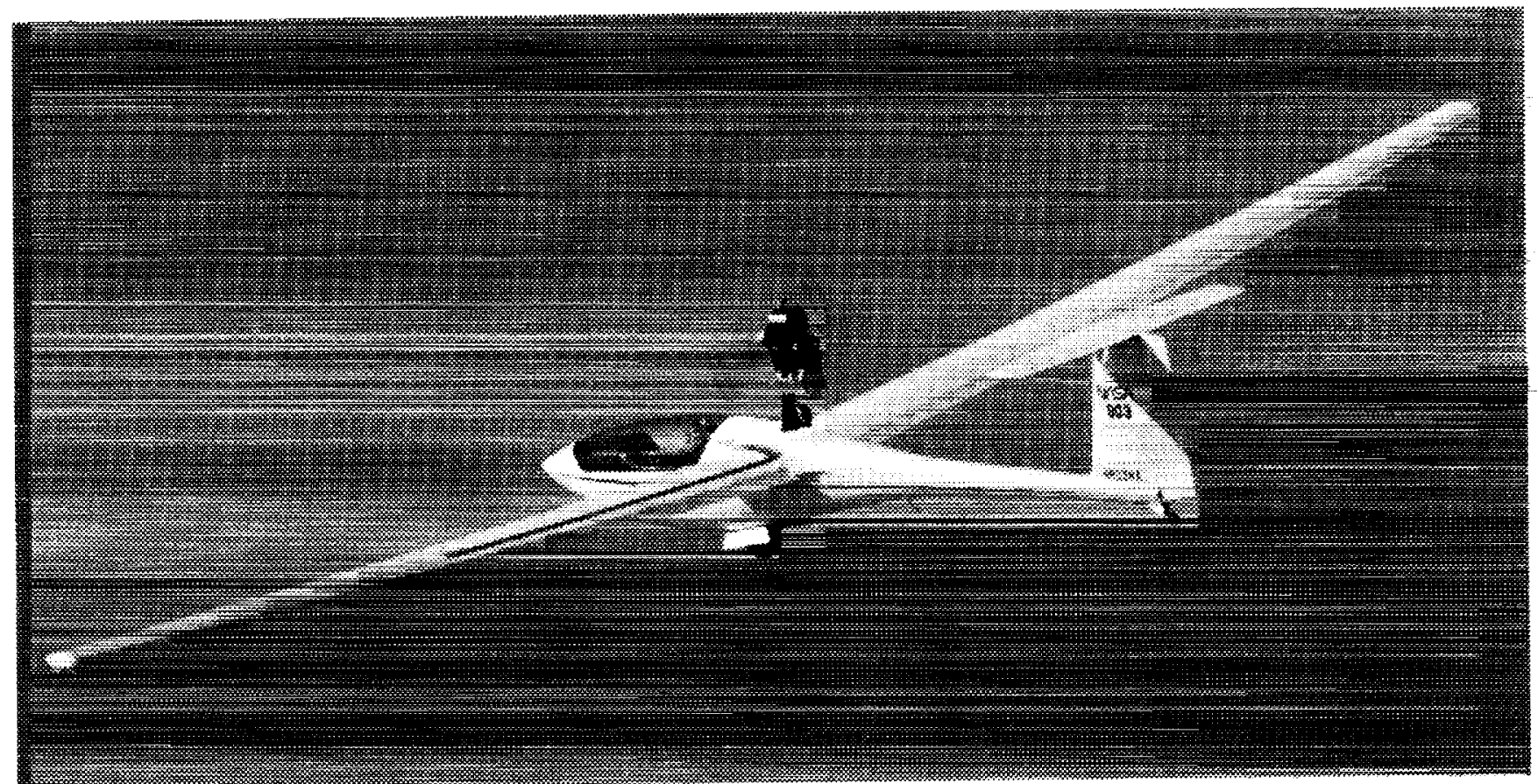

EC 91 504-1

Fig. 8 PIK 20E self-launching sailplane.

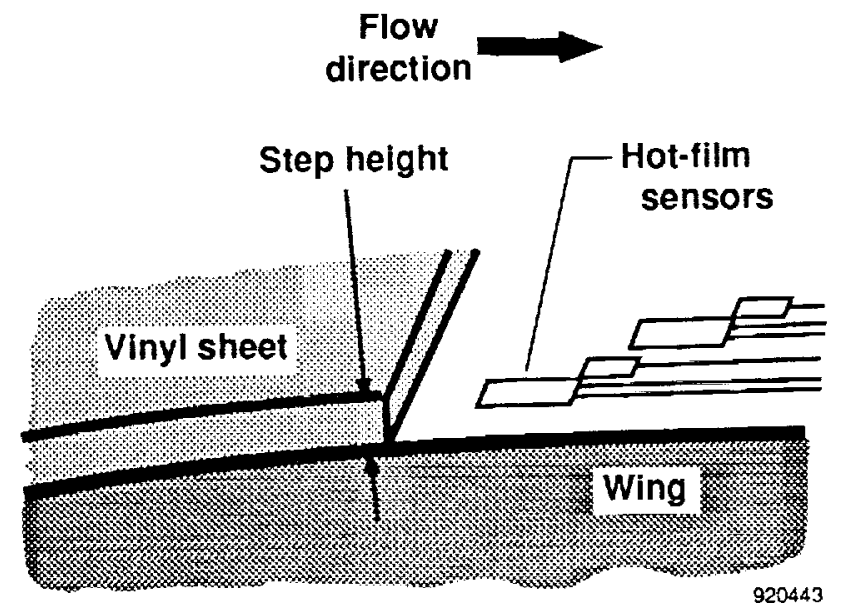

Fig. 9 Cross-sectional view of the test excrescence.

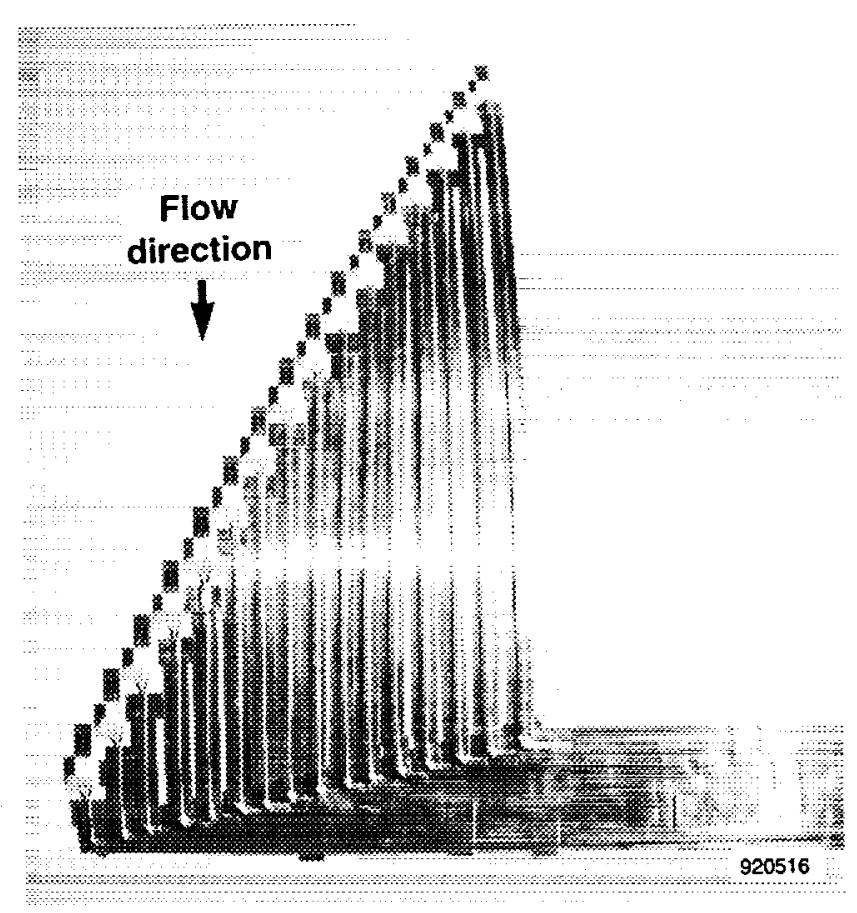

Fig. 10 Hot-film sensor array on wing. 


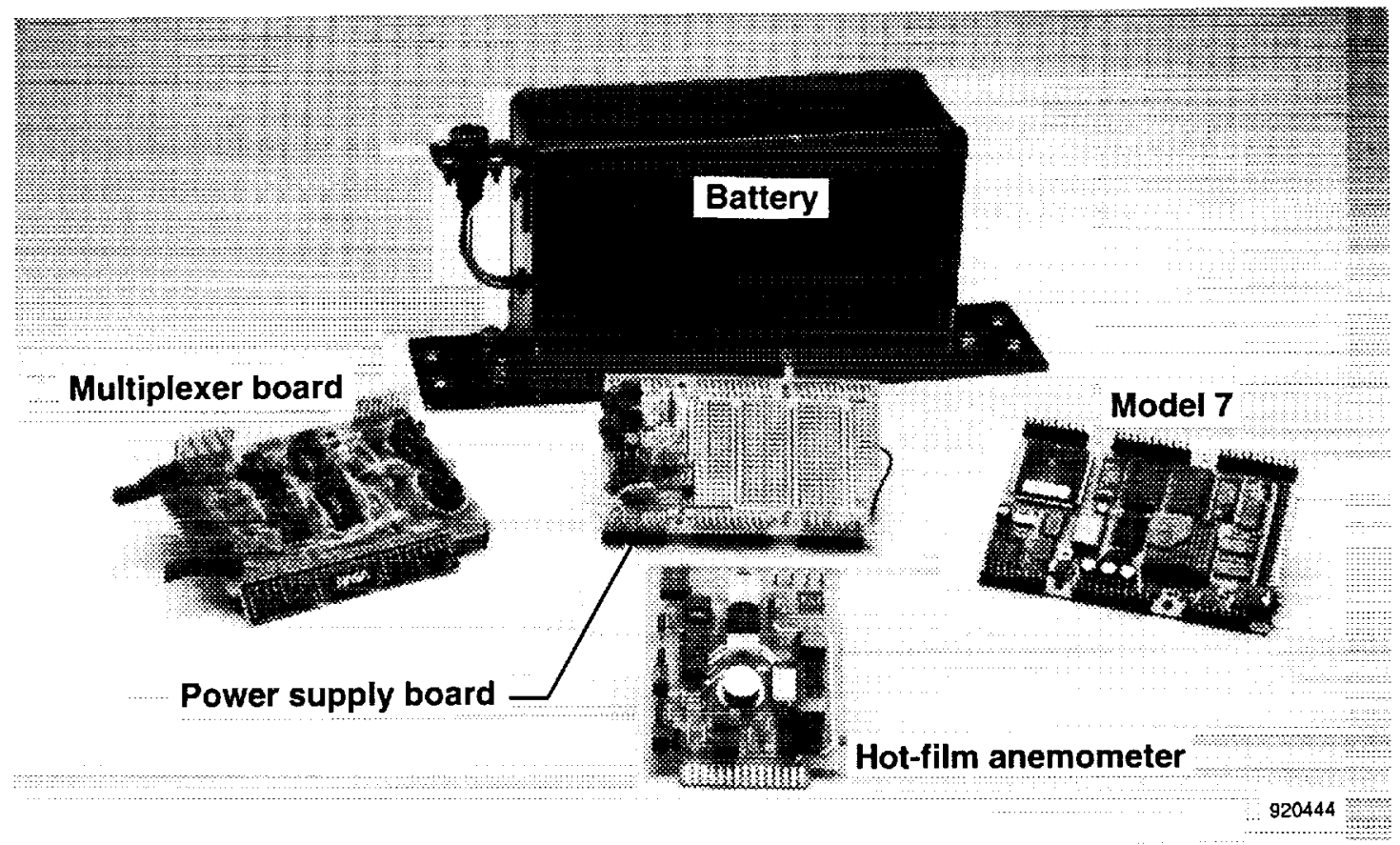

Fig. 11 Signal conditioning, data logging, and power components of Model 7-based data acquisition system.

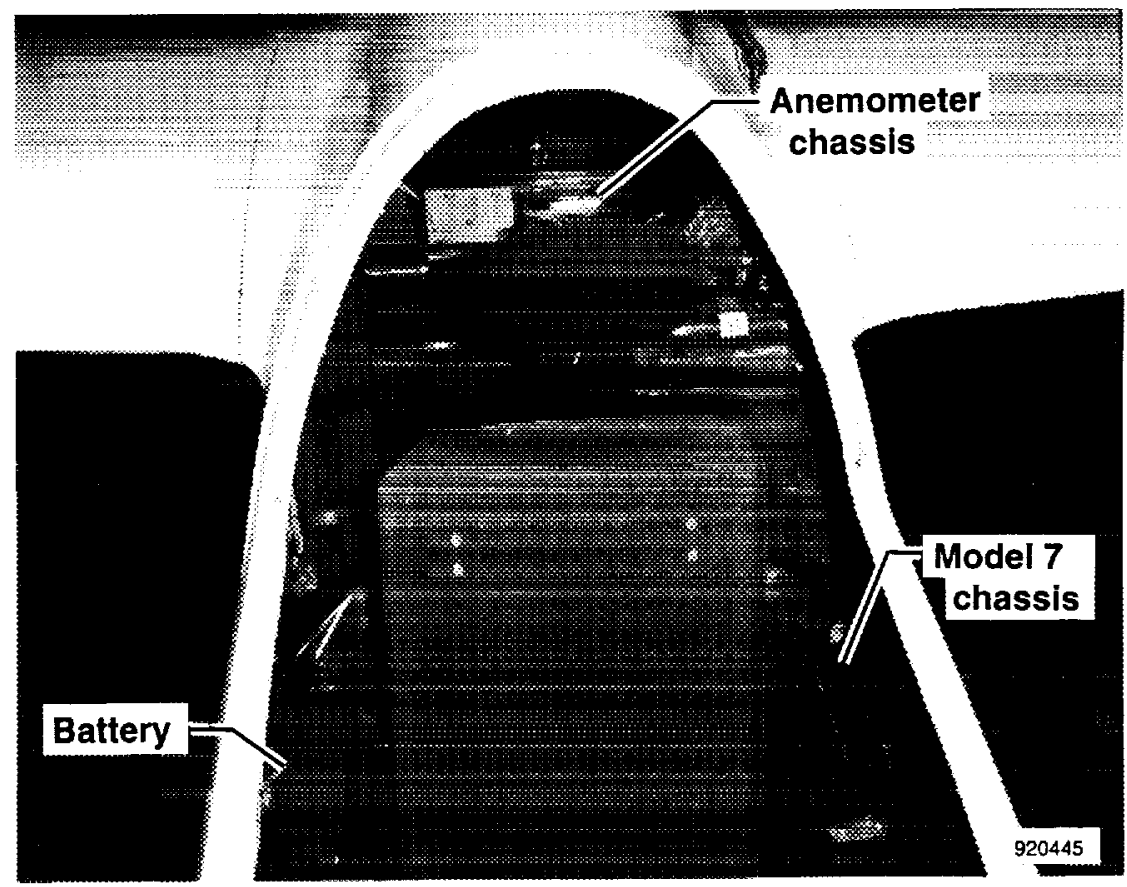

Fig. 12 Instrumentation installation in sailplane cockpit. 


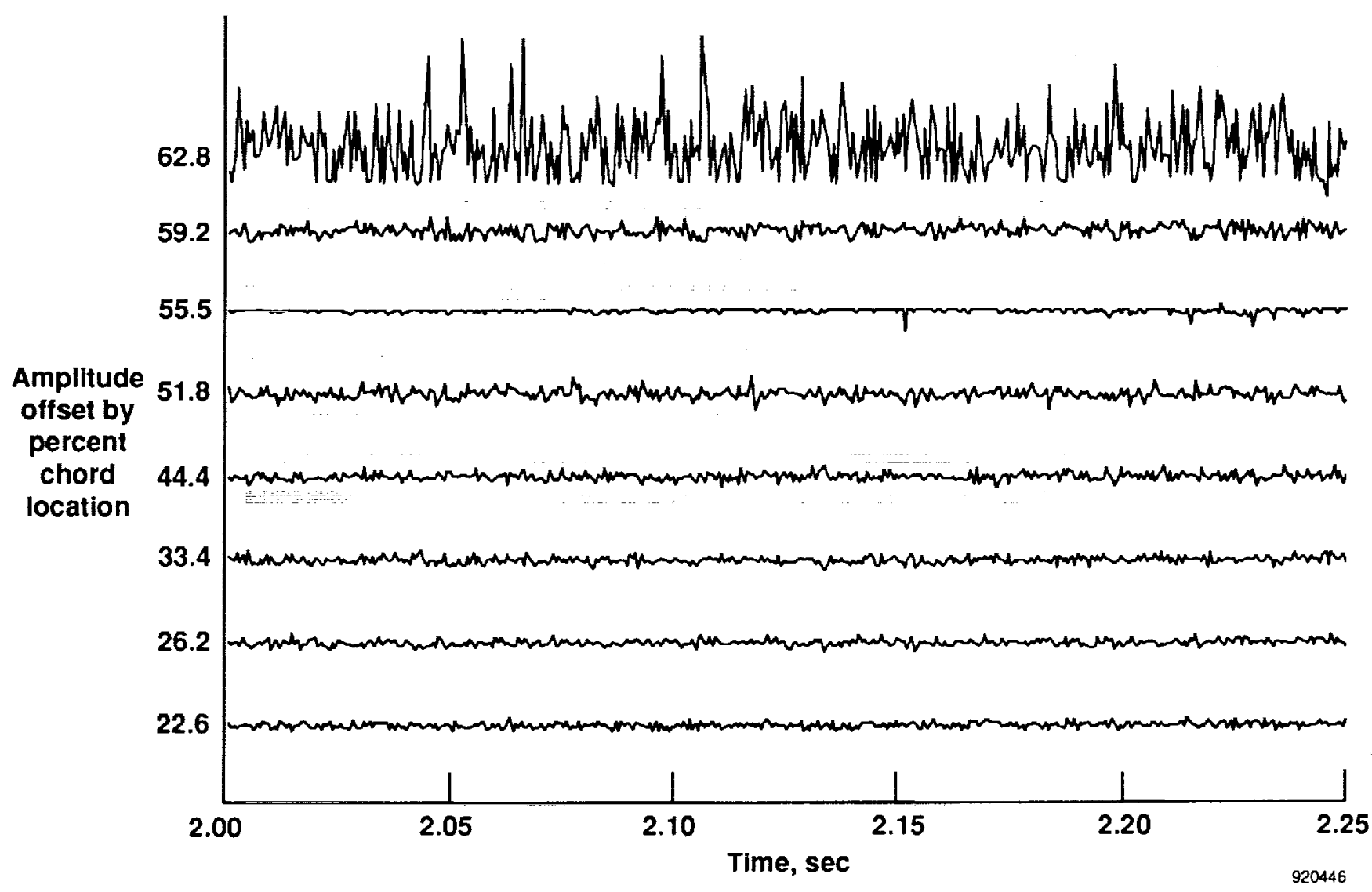

Fig. 13 Time history of hot films on smooth wing at 70 knots.

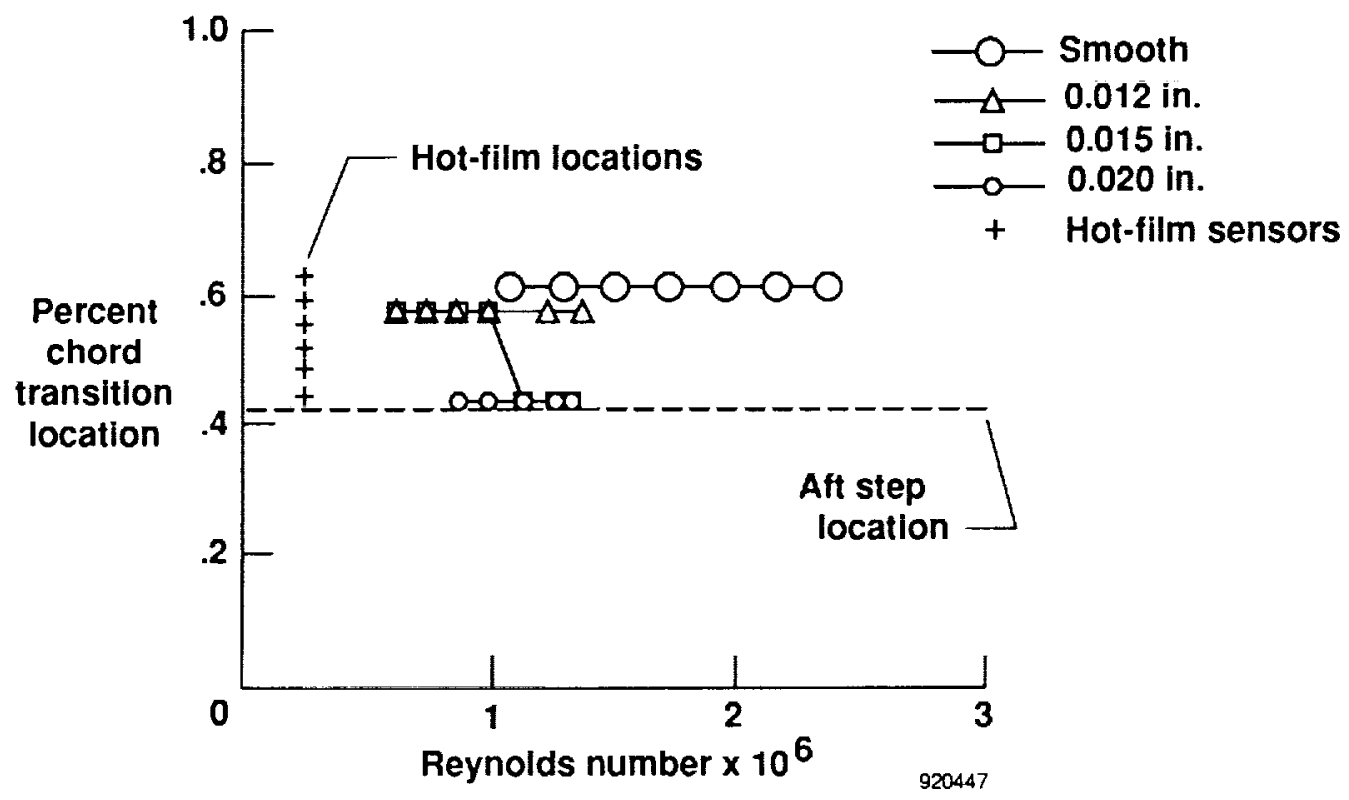

Fig. 14 Transition location for aft step configuration at 42.6-percent chord. 


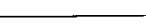






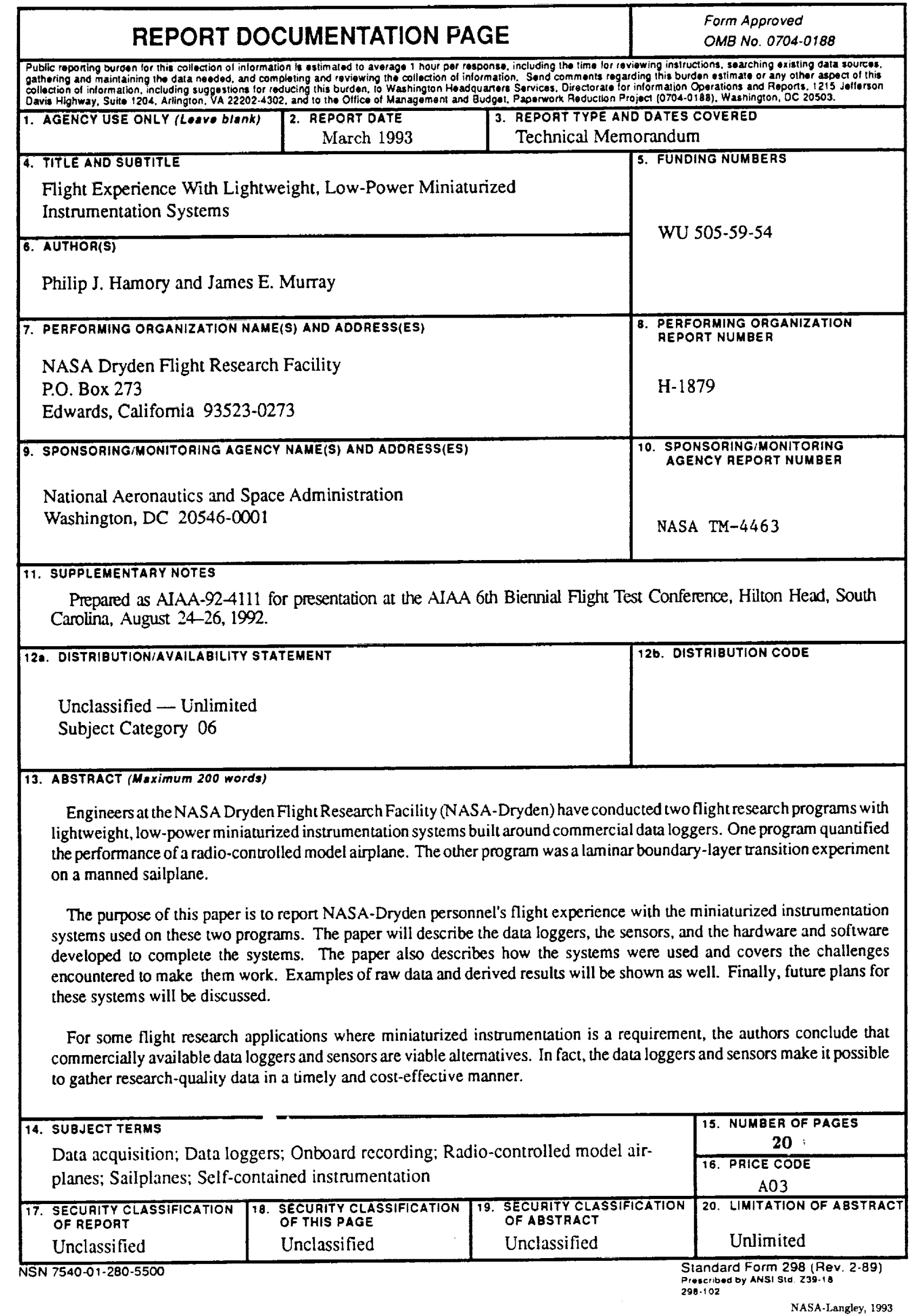

